\title{
THE NEOTROPICAL SPECIES OF THE ANT GENUS STRUMIGENYS FR. SMITH: GROUP OF GUNDLACHI (ROGER) ${ }^{1}$
}

\author{
By William L. Brown, JR. \\ Museum of Comparative Zoology, Harvard University
}

This paper is a continuation of my series on the New World fauna of the dacetine ant genus Strumigenys Fr. Smith. Earlier parts, containing keys to the abbreviations for measurements and proportions, may be found in Jour. New York Ent. Soc. 6r : 53-59, IOI-I IO (1953). In addition to these, other parts have been published or are being prepared. At the end of the series, an illustrated key to the New World members of the genus will be forthcoming.

\section{Relationships of the gundlachi Group}

The present section deals with a group approximately equivalent to what I called in my preliminary generic revision of the Dacetini (Brown, 1948, Trans. Amer. Ent. Soc., 74: IOI-I29) by the name Strumigenys subgenus Pyramica. At that time, the group seemed rather distinct from all the other Strumigenys species on the basis of the following characters:

I. Mandibular insertions more remote.

2. Apical fork of mandible with more or less reduced teeth.

3. Inner mandibular border with a series of three or more denticles, instead of two, one or no preapical teeth in Strumigenys s. str.

4. Antennal scapes shorter and broader.

5. Spongiform appendages of petiole and postpetiole reduced.

6. Labral lobes longer.

7. General habitus, especially head shape.

Since 1948 , I have had the opportunity to study carefully the three species recently described by Kempf (1958, Rev. Brasil. Ent., 8: 5968 ) as the $S$. connectens group, which bridges very nicely the gap between Pyramica and the more typical Strumigenys - in particular, the $S$. louisianae group. The steps from Strumigenys to Pyramica are so gradual that it is clear only an arbitrary distinction can now be drawn between the two groups. Under these circumstances, there is no need for a formal generic or subgeneric split, and the name Pyramica goes into the synonymy of Strumigenys. (The one other

\footnotetext{
${ }^{1}$ Published with the aid of a grant from the Museum of Comparative Zoology at Harvard College.
} 
subgenus of Strumigenys is Labidogenys Roger, which also deserves synonymy from present evidence.) In the present paper, "gundlachi group" is used, instead of Pyramica, to include the species gundlachi (Roger), eggersi Emery, subedentata Mayr, denticulata Mayr, jamaicensis Brown and trieces n. sp. It should be emphasized, however, that the group is arbitrarily limited, and that $S$. connectens and its relatives could as well be included as not.

\section{The Identity of Pyramica gundlachi Roger}

Roger described Pyramica gundlachi in I862, only two years after Frederick Smith had established Strumigenys. Roger based his species on worker and female specimens from Cuba. Roger himself quickly ( I 863) recognized that gundlachi was so close to Strumigenys that Pyramica would have to fall as a synonym of that genus. In I 890, Emery demonstrated that gundlachi was a composite species; the female was then named as Strumigenys rogeri Emery, a distinct species we now know to have been introduced into Cuba from Africa.

In the meantime Mayr ( I887) had recharacterized gundlachi from a cotype worker that Roger had sent him earlier. Both Roger and Mayr described gundlachi as having the inner mandibular border unarmed before the apex and as having the ventral apical tooth divided. The remainder of the information available indicated to me that gundlachi, despite these characters and despite the fact that subsequent authors had described varieties in this complex as having unarmed preapical masticatory borders, belonged with a group including eggersi, denticulata and subedentata and their varieties and synonyms. Accordingly (without then knowing the connectens group) I revived Pyramica as a subgenus with gundlachi as the (monobasic) type species (Brown, I948).

From I 887 until 1948 , the true gundlachi was ignored by most authors, and its identity wrongly guessed by several others. Finally, through the kindness of the late Prof. Bruno Pittioni of the Vienna Museum, I was able to examine the critical syntype worker that Roger had sent to Mayr. The mandibles of this specimen turned out to be encrusted with ancient glue, and, since this was the only specimen in Mayr's collection, it seems clear that he merely followed Roger in describing the mandibles. The glue was carefully removed with Barber's fluid, revealing that the mandibles have a full complement of preapical denticles and a normal apical fork with two minute intercalary denticles. In short, the gundlachi syntype was found to be 
identical with types of $S$. eggersi infuscata Weber and with many other samples from the Caribbean area in the MCZ. It became evident that most of the forms originally described as varieties of $S$. eggersi were in fact only variants of gundlachi. Later, Dr. E. M. Hering, of the Zoologisches Museum in Berlin, kindly confirmed the same points for the remaining gundlachi syntypes in the Roger Collection.

Relationship and Synonymy of $S$. gundlachi and S. eggersi

Early in the study, $S$. denticulata and $S$. subedentata (with its synonyms clavata and tristani) were recognized as distinct species. Later, the new species jamaicensis and trieces were discovered and set to one side. The large residue of samples available in the gundlachi group all appeared to fall into one complex of very similar but variable forms. On further study, this complex was resolved into two morphological species, one corresponding to the gundlachi type, and the other to syntypes of eggersi in the USNM, differentiated by the characters cited in the description below and shown in Figs. 7 and 8 . There remained the task of determining the identity of the six subspecies and varieties assigned to eggersi by various authors: var. vincentensis Forel, var. cubaensis Mann, var. banillensis Santschi, var. isthmica Santschi, subsp. infuscata Weber and var. berlesei Weber. Of these, vincentensis, cubaensis and banillensis were all described as lacking preapical denticulation on the mandibles. The types of cubaensis were examined first; these are specimens of Strumigenys louisianae Roger, and have been synonymized accordingly (Brown, 1953, Amer. Midl. Nat., 50: 28-29.). A worker type of banillensis from the Santschi Collection proved to have partly broken but distinct preapical denticulation, and it agreed well otherwise with gundlachi. The unique type of vincentensis cannot be found in the British Museum or in the Forel Collection; it is almost certainly just another gundlachi specimen in which the denticulae were overlooked, judging from the description and locality. Types of infuscata and berlesei were compared with the gundlachi lectotype, and these names are judged to be straight synonyms. The description of isthmica agrees well with the types and Panamanian samples of gundlachi. All named variants of eggersi are thus accounted for. There is one more name: $S$. bierigi Santschi. The description of this form from Cuba fits the typical gundlachi so well that there seems no reason to doubt its synonymy; gundlachi is the most common 
species of the group so far found on Cuba. The status of the names involved is summarized in list form:

Group of S. gundlachi

gundlachi (Roger)

=eggersi var. vincentensis Forel n. syn.

=eggersi var. banillensis Santschi n. syn.

=bierigi Santschi n. syn.

=eggersi var. isthmica Santschi n. syn.

=eggersi subsp. infuscata Weber n. syn.

=eggersi var. berlesei Weber n. syn.

eggersi Emery

denticulata Mayr

subedentata Mayr

=tristani Menozzi n. syn.

= clavata Weber n. syn.

jamaicensis Brown

trieces $\mathrm{n}$. sp.

Strumigenys gundlachi (Roger)

(Figures I, 5)

Pyramica gundlachi Roger, 1862: 253. pl. 1, fig. 18a, worker nec female. Type loc.: Cuba. Lectotype, by present designation, the worker specimen in Naturhistorisches Museum, Vienna. Other syntypes in Zoologisches Museum der Humboldt Universitat, Berlin. Lectotype examined.

Strumigenys gundlachi, Roger, 1863, Verz. Formic., p. 40. Mayr, 1887: 570, worker.

Strumigenys eggersi var. vincentensis Forel, 1893, Trans. Soc. Ent. London, p. 378, worker. Type loc.: Forest near Châteaubelaise, $1000 \mathrm{feet}$, St. Vincent, B. W. I. Location of type unknown, presumed lost. New synonymy.

Strumigenys eggersi var. banillensis Santschi, 1930: 80, worker. Type loc.: Sierra Banilla, near Habana, Cuba. Unique holotype in Santschi Coll., Basel; examined. New synonymy.

Strumigenys bierigi Santschi, 1930: 80, worker. Type locs.: (1) Marianao, Cuba; (2) La Habana, Cuba. Types in Santschi Coll., Basel; not seen. Santschi, 1931: 276, worker variation. New synonymy.

Strumigenys (Strumigenys) eggersi var. isthmica Santschi, 1931: 276, worker. Type loc.: France Field, Panama. Syntypes in Santschi Coll., Basel. New synonymy.

Strumigenys (s. str.) eggersi subsp. infuscata Weber, 1934: 35, worker, female. Type loc.: Limones Seboruco, Soledad, Cuba. Syntypes in MCZ, Coll. Weber. New synonymy.

Strumigenys (s. str.) eggersi var. berlesei Weber, 1934: 36, female. Type loc.: Harvard Botanical Gardens, Soledad, Cuba. Holotype in Coll. Weber, examined. New synonymy.

Nec Strumigenys gundlachi of Creighton (1930, Psyche, 38: 179, fig. 1 A), which is based upon a worker from what later became the type series of $S$. caribbea Weber. $S$. caribbea was formally synonymized with $S$. silvestrii Emery by Brown, 1959, Stud. Ent. (n. s.), 2: 25. 
Worker: TL I.7-2.I, HL 0.40-0.49, ML 0.24-0.32, WL 0.4O$0.50 \mathrm{~mm}$. CI 79-86, MI 59-66.

This variable species is small and rather slender, with convex head and alitrunk, the latter with a weak but readily discernible metanotal groove and acute, oblique propodeal teeth with concave, cariniform infradental lamellae. Mandibles straight, inner borders straight to weakly convex, with 4-9 preapical denticles along the apical half or more, which are very variable in size, shape and spacing in different samples, and are often very difficult to see except in dark silhouette against a bright background. The three most distal teeth are often larger than the rest, but sometimes all of them are extremely small. The dorsal tooth of the apical fork is short, but is longer than its ventral mate; between them are two minute intercalary denticles. Petiole and postpetiole shown in Figure 5; note the small but still distinct spongiform appendages.

Body generally densely reticulate-punctulate, opaque, although in some examples the lower posterior sides of the alitrunk may have the sculpture partly effaced and shining. Gaster smooth and shining when clean, with distinct spaced longitudinal carinae taking up about the basal quarter or so of the first segment. Sometimes faint traces of shagreened sculpture also occur on the basal half of the gastric tergum, and some specimens are fouled with dirt or hardened secretion, so that it becomes difficult to tell them from eggersi workers in this respect.

Ground pilosity of head and promesonotum consisting of slender, curved, decumbent, linear-spatulate hairs, numerous on head but sparse on promesonotum. Fringing hairs of head shown in Figure I. Mandibles with fine subappressed pointed hairs, and a row of short oblique pointed hairs along each inner mandibular border. Longer erect hairs are mostly slender, truncate to feebly remiform or clavate: one pair on vertex, one pair on occiput, one or two pairs on petiolar node, two or three pairs on postpetiole, and 30-45 hairs on gastric dorsum, arranged more or less in transverse rows. In addition, there are bilaterally paired erect hairs which may be either long and flagelliform or short and paddle-shaped (remiform). Apparently, remiform hairs are readily transformed into flagelliform ones by the detachment of the rim of the hair at one side, so that the hair frays out to a long, slender point. Flagelliform hairs are often seen reflexed or looped, like a furled coachwhip, and it is difficult to distinguish such hairs from the remiform ones. One of these hairs is to be found on each lateral occipital convexity (Figure I), and there is a pair on the 

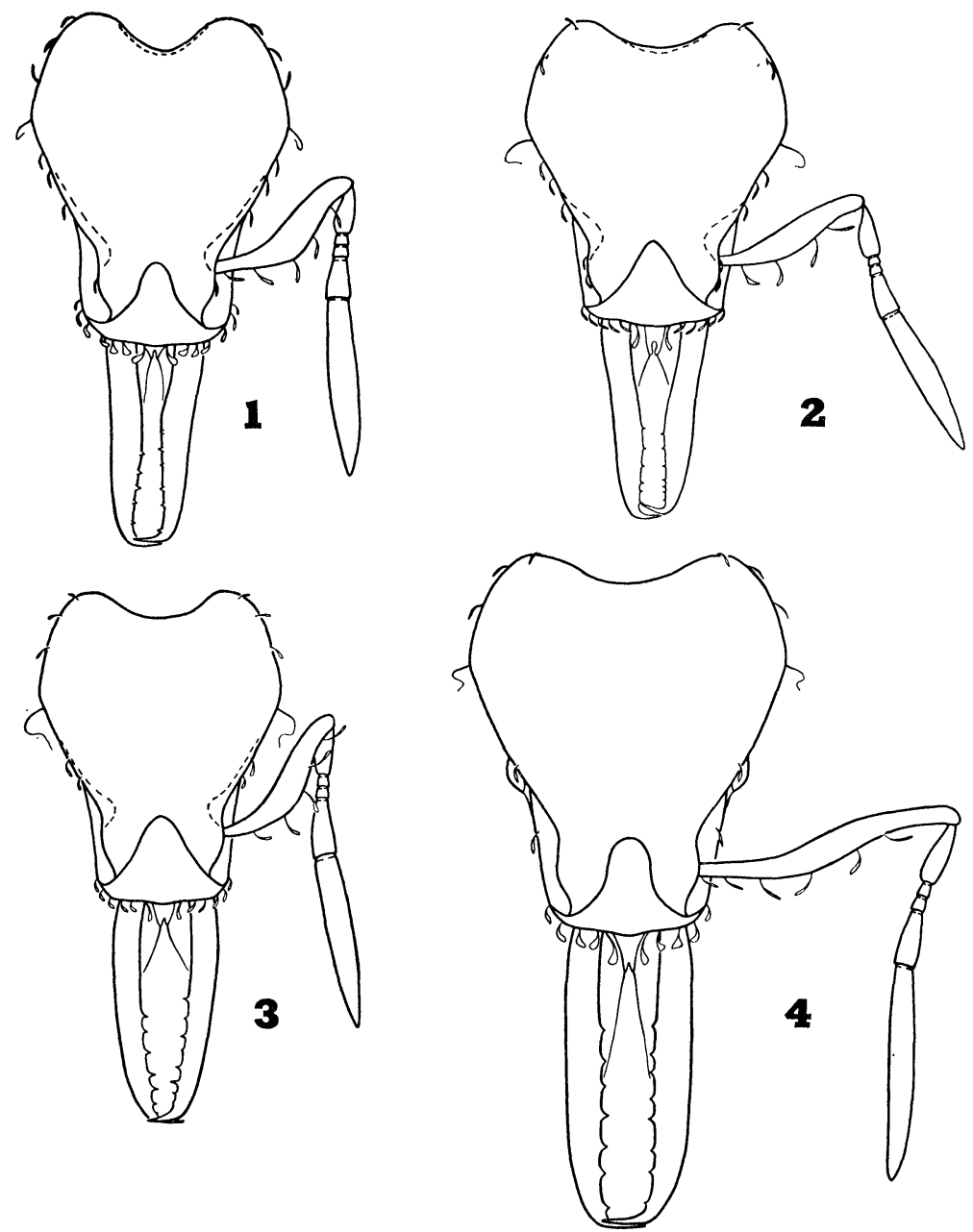

Figures 1-4. Strumigenys of the gundlachi group, heads of workers, right antenna omitted; only the fringing pilosity is shown, and mandibular hairs are omitted. Figure 1, $S$. gundlachi (syntype of the synonymous $S$. eggersi infuscata from Cuba). Figure 2, S. eggersi from S. Teresa, Espiritu Santo, Brazil. Figure 3. S. denticulata from Trinidad. Figure 4. S. jamaicensis, paratype. Drawn to same scale. 

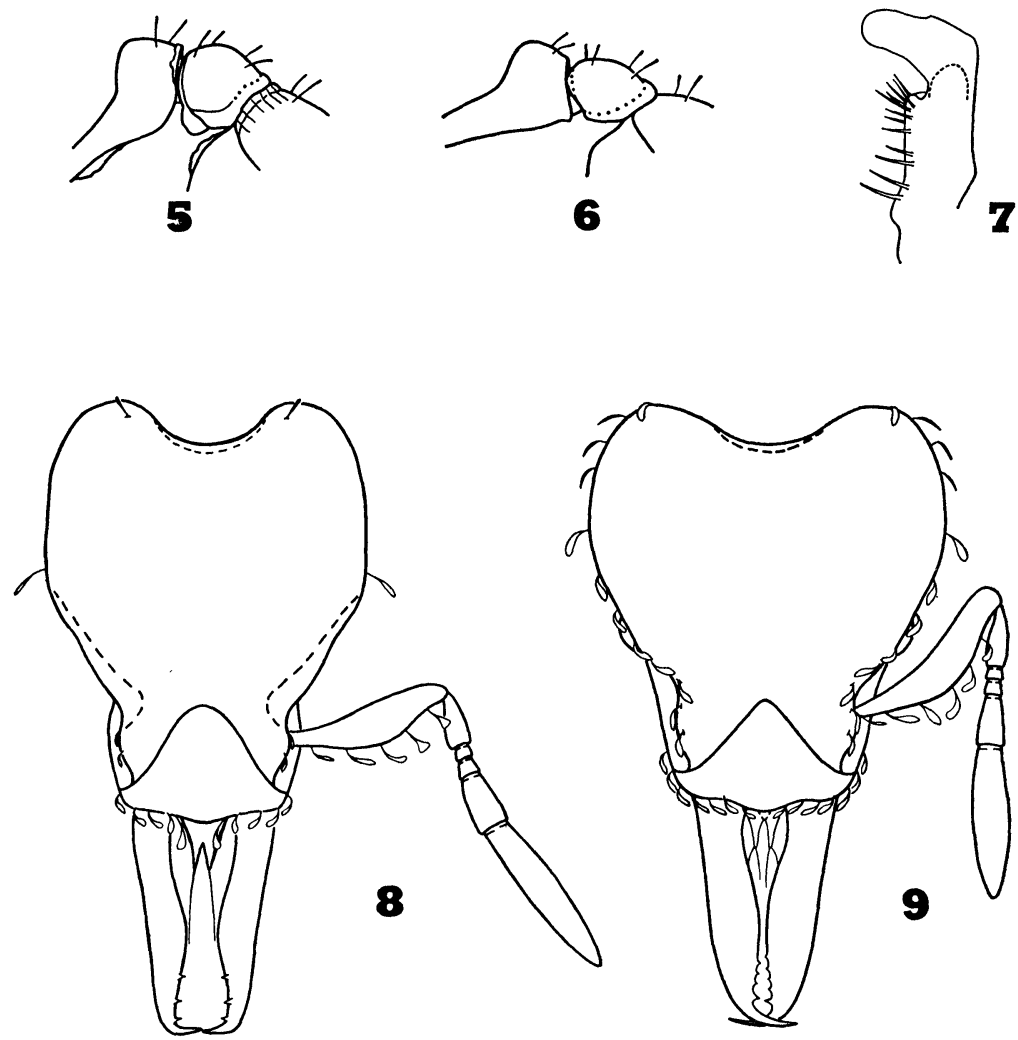

Figures 5-9. Strumigenys of the gundlachi group. Figure 5, S. gundlachi, side view of pedicel to show spongiform appendages; same specimen as Figure 1. Figure $6, S$. eggersi, side view of pedicel, same specimen as Figure 2. Figure 7, S. subedentata male, volsella of genitalia, Mixco, Guatemala. Figure 8, Strumigenys trieces, new species, holotype worker. Figure 9, $S$. subedentata, worker from Panama Canal Zone. Figures 5, 6, 8 and 9 are drawn to the same scale as Figures 1-4; Figures 8 and 9 carry the same conditions as 1-4. 
humeri and a pair on the mesonotum. The pilosity varies in different samples, however, and specimens are frequently partly denuded. Color usually medium ferruginous, but some samples are much darker; a Jamaican series is blackish-brown.

The female is similar to the larger workers of the same nest series, apart from the usual caste differences, but the head averages a trifle broader (CI 83-89), and the gastric dorsum is more or less distinctly shagreened over the basal segment, but usually not so strongly sculptured as is the eggersi female. Male unknown.

Distribution: Occurs widely in countries bordering the Caribbean; actually reported from southern Mexico, Costa Rica and Panama; Central America may be the original home of the species. It is well established in Trinidad and Tobago, Cuba and Jamaica, and southern Florida, doubtless after introduction through human commerce, at least in some of these places, but it has not been found on the South American mainland.

Localities for material examined: Trinidad: Laboratory at Simla, 800 feet, 4 miles north of Arima (R. Foster leg.). Arima-Blanchiseusse Road (N. A. Weber leg.). Arima (Weber leg.). Macqueripe Bay (Weber leg.). St. Augustine (Weber leg.). Tobago Island: (R. Foster leg.). Jamaica: near Round Hill, Manchester Parish (H. B. Mills leg.). Southfield and Black River, St. Elizabeth Parish (Mills leg.). Cuba: various collections in and near Soledad, Las Villas Prov. (leg. M. Bates and G. Fairchild, E. O. Wilson, N. A. Weber), including types of infuscata and berlesei. Mina Carlota, Trinidad Mts. (Wilson leg.). Baragua, Camaguey (Bates and Fairchild leg.). Florida, U.S. A.: Royal Palm Ranger Station, Everglades National Park (L. J. Stannard leg.). Northern Key Largo (E. O. Wilson leg.). Mexico: Pueblo Nuevo, near Tetzonapa, Veracruz (Wilson leg.). Villa Hermosa, Tabasco (F. Bonet leg.). Finca el Real, Ocosingo Valley, Chiapas (Goodnights and Stannard leg.). Costa Rica: without further locality (leg. H. Schmidt, F. Nevermann). Panama Canal Zone: Barro Colorado Island, many collections by J. Zetek, E. S. McCluskey, W. L. Brown, Jr., and others.

Biology : E. O. Wilson (unpubl. notes) kept a colony of gundlachi for over a month in Cuba, during which time it captured and consumed entomobryoid and sminthurid collembolans, but ignored poduroids, a small cricket nymph, various mites and minute millipeds. Hunting is usually of the relatively immobile ambush type, which is to say that the ants approach the prey and, when close enough to de- 
tect its position, freeze with mandibles held open toward it (at an angle of $60^{\circ}-70^{\circ}$ in this case). However, sometimes workers approach the prey and strike quickly and directly, without waiting. If prey is struck and continues to struggle, it is lifted off the ground and stung in the usual manner of Strumigenys.

McCluskey and I found this species in nearly every berlesate of upper soil and leaf litter that we examined on Barro Colorado Island; it is evidently there the most common dacetine species and one of the more frequent ant species of the forest floor. Wilson found gundlachi to be somewhat less abundant in Veracruz. Although it is abundant in tropical rain forest, it also lives in second-growth forest, thickets, and cacao plantations. Weber (1952) took a sample deep in a cave on Trinidad among manure and debris from the oil-birds (Steatornis) and bats living there.

\section{Strumigenys jamaicensis Brown}

(Figure 4)

Strumigenys jamaicensis Brown, 1959, Brev. Mus. Comp. Zool., 108: 6, worker. Type loc.: Corn Puss Gap, 2000 ft., St. Thomas Parish, Jamaica. Holotype in Coll. Illinois State Natural History Survey, Urbana, Illinois; paratypes in $\mathrm{MCZ}$.

Worker: TL 2.3-2.6, HL 0.52-0.56, ML 0.40-0.42, WL 0.55-0.57 $\mathrm{mm}$. CI 8I-82, MI 75-77.

Resembles $S$. gundlachi, but larger and with relatively much longer mandibles and antennae, particularly the scapes. Mandibles with gently convex outer borders and straight inner borders bearing 6-8 strong, acute denticles which occupy about the distal $2 / 3$ of the border. Body in general relatively more slender than in gundlachi. Sculpture, pilosity and spongiform appendages as in gundlachi, although in jamaicensis the ground pilosity tends to be less conspicuous and the erect hairs larger; also, the gastric hairs are larger and fewer. Color blackish-brown. Female and male unknown.

In addition to the holotype nest series from Corn Puss Gap, I studied two additional (paratype) series from Hardwar Gap (about 4000 feet), Portland Parish, Jamaica. All of the specimens were taken by H. B. Mills by Berlese funnel from soil-leaf litter charges.

Distribution and relationships: So far as is known, this species is confined to the mountains of Jamaica. It appears to be a specialized descendant of an early immigrant population derived from the mainland gundlachi stock. Both gundlachi and eggersi now also occur on Jamaica, probably as a result of accidental introduction by man, but 
there is no evidence of intergradation between jamaicensis and either of these species.

\section{Strumigenys eggersi Emery}

(Figures 2, 6)

Strumigenys eggersi Emery, 1890: 69, pl. 7, fig. 9, worker, female. Type loc.: St. Thomas, West Indies. Syntypes in Museo Civico di Storia Naturale, Genova, and in USNM, several examined.

Strumigenys (Strumigenys) eggersi, Santschi, 1931: 276 (records from Pinar del Rio Prov., Cuba, and key to "varieties.").

Worker: TL i.6-2.0, HL 0.39-0.47, ML 0.22-0.27, WL 0.39$0.46 \mathrm{~mm}$. CI $83-88$, MI 56-64. Very similar to $S$. gundlachi, averaging a little smaller, with relatively shorter mandibles, although dimensions and proportions of the two species overlap broadly. Mandibles straight, with weakly convex inner borders, each bearing $4-8$ minute denticles on its distal I/3 to I/2. Color yellowish ferruginous, lighter than usual for gundlachi. The two chief characters are these:

I. Spongiform appendages of petiole and postpetiole obsolete, the lateral postpetiolar lobes represented by a narrow lamellate margin (Figure 6).

2. First gastric tergum superficially reticulate-punctulate and opaque in front, becoming indefinitely shagreened and weakly shining behind.

The female differs from the workers in the same way that the gundlachi queen differs from its workers. Reticulate sculpture of gastric dorsum more distinct and more opaque than in worker. Male unknown.

Distribution: The home range is probably southern Brazil and Bolivia, though lack of collections from central and northern Brazil prevents us from knowing how far north this species extends. $S$. eggersi is also known from widely scattered localities in the West Indies, Florida and southern Mexico, sometimes sympatrically or nearly so with $S$. gundlachi, and it seems likely that it has been introduced by man at these points.

Localities for material examined: Bolivia: Espia Rio Bopi (W. M. Mann leg.). Brazil: Agudos, S. Paulo State (W. W. Kempf and C. Gilbert leg.). Rio de Janeiro (T. Borgmeier leg.). Santa Teresa, Espiritu Santo State (O. Conde leg.). West Indies: Trinidad (P. B. Whelpley leg.). Pitch Lake and Trinity Hills Forest Reserve, Trinidad (N. A. Weber leg.). Roseau, Dominica (Weber leg.). St. Thomas (Baron Eggers leg.), syntypes of eggersi, in USNM. Maya- 
guëz, Puerto Rico (M. R. Smith leg.). Petit Goave and Fond Verrettes-Refuge, Haiti (H. B. Mills leg.). Jamaica: Spanish Town, St. Catherine Parish; Mt. Diablo, St. Ann Parish; Black River, St. Elizabeth Parish; Heron's Hill, Manchcster Parish (all Mills leg.). Soledad, Las Villas Prov., and San Vicente, Pinar del Rio Prov., Cuba (E. O. Wilson leg.). Florida, U. S. A.: Fisher's Island (J. E. Porter leg.). Archbold Biological Station, Highlands County ( $\mathrm{H}$. S. Dybas leg.). Mexico: Palmillas, Tabasco (F. Bonet leg.). Chichen Itza, Yucatan (L. J. Stannard leg.).

Biology: Weber found specimens in a compost heap in the Botanical Garden at Roseau, Dominica, and in an island of vegetation growing in the Pitch Lake of Trinidad; also on Trinidad, he took a sample from low-growing epiphytes in second-growth forest. Kempf sifted specimens from humus in São Paulo. Indications are that this species can stand more dryness than many dacetines, and its presence in many culture areas suggests that it is spreading rapidly through nursery stock transport and other human commerce. The Floridian records for both this species and gundlachi are the first for the continental United States.

\section{Strumigenys denticulata Mayr}

(Figure 3)

Strumigenys denticulata Mayr, 1887: 576, worker. Type loc.: Blumenau, S. Catarina State, Brazil. Types in Naturhistorisches Museum, Vienna, and in $\mathrm{MCZ}$; two workers examined. Emery, 1890: pl. 7, fig. 8, worker.

Worker: TL 1.8-2.2, HL 0.42-0.48, ML 0.3I-0.39, WL 0.42$0.49 \mathrm{~mm}$. CI 77-80, MI 74-83. Similar to gundlachi and eggersi, but more slender, and with very long, slender, slightly bowed mandibles, each bearing 5-9 denticles along the distal half or more of their inner borders. The antennae are also proportionately long and slender. Spongiform appendages obsolete, like those of eggersi. Sculpture as in eggersi, except that the gaster is predominantly smooth and shining, with only a weak basal shagreened band. Color yellowishferruginous to medium ferruginous.

Female with stronger and more extensive reticulation on gaster, covering nearly the entire dorsum of the first segment.

Distribution: Known from widely scattered localities in South America, reaching from northern Argentina to the Guianas and Trinidad. It probably ranges through much of central Brazil, whence no collections of ants are available from Berlese samples.

Localities for material examined: Argentina: Ing. Juarez, Formosa Prov. (N. Kusnezov leg.). Brazil: Blumenau, S. Catarina State 
(Hetschko leg.), syntypes of denticulata in MCZ. Itapecirica, S. Paulo State (Kempf and Santos leg.). Agudos, S. Paulo State (C. Gilbert, W. W. Kempf leg.), several series. Belem, Pará State (C. R. Gonçalves). British Guiana: Kartabo Point, and Forest Settlement on the Mazaruni River (N. A. Weber leg.). Trinidad: Trinity Hills Forest Reserve (Weber leg.).

Biology: According to Weber ( 1952 ), this species occurs in both primary forest and second-growth, in leaf litter or in rotten twigs of low epiphytes. Kempf ( 1958 ) took it in humus, and Wasmann ( I915) reports a sample taken in a nest of Anoplotermes in southeastern Brazil.

\section{Strumigenys subedentata Mayr}

(Figures 7, 9)

Strumigenys subedentata Mayr, 1887: 570, 575, worker. Type loc.: "St. Catharina," Brazil. Syntypes in Naturhistorisches Museum, Vienna, and MCZ, two examined. Emery, 1890: pl. 7, fig. 11, worker.

Strumigenys tristani Menozzi, 1931, Boll. Lab. Zool. Portici, 25: 273, fig. 8, worker. Type loc.: Orijuaco, Costa Rica. Syntypes in MCZ and Coll. Consani (Bologna), several examined. New synonymy.

Strumigenys (s. str.) clavata Weber, 1934: 32, fig. 8, worker. Type loc.: Trece Aguas, Alta Vera Paz, Guatemala. Syntypes in MCZ, examined. New synonymy.

Worker: TL 2.0-2.4, HL 0.48-0.56, ML 0.26-0.30, WL 0.47-0.6o mm.; CI 82-86, MI 53-54. Larger and more robust than gundlachi and eggersi on the average. Mandibles thick, with distinctly convex inner margins; apical fork with a long dorsal and a short ventral teeth, plus two minute intercalary denticles. Close to the dorsal apical tooth is a small preapical tooth or denticle, followed closely proximad by 3-5 smaller denticles, confined to about the apical third of the inner margin.

Promesonotum convex, separated from propodeum by a distinct metanotal groove; humeral angles blunt. Propodeal teeth large, slightly raised, infradental lamellae reduced to carinae. Petiole with long peduncle and rounded node, spongiform appendages reduced to a cariniform posterodorsal collar. Postpetiole subreniform, distinctly wider than petiolar node, but less than half as wide as gaster; its spongiform appendages vestigial, approaching the state of those of the eggersi worker. Gaster without spongiform appendages.

Body and appendages densely reticulate-punctulate, opaque; gastric dorsum with a more or less distinct superimposed longitudinal striation. Underside of gaster, and sometimes also the posterior part of the gastric dorsum, with the sculpture more or less effaced and shining. 
Pilosity conspicuous and abundant, particularly on head. Ground hairs spoon-shaped, subreclinate, curved forward and more or less mesad on dorsum of head; mandibular hairs pointed, dense, appressed, except for the row of large oblique hairs on each inner margin. A very few inconspicuous, narrowly spoon-shaped hairs on promesonotum. Larger, erect, remiform to clavate hairs: 2 pairs on head (Figure 9); one humeral and one median pair on pronotum; 3-5 pairs on mesonotum; 2 pairs on petiolar node; 3 pairs on postpetiole; about 6 rows of 6 hairs each on gastric dorsum.

Color medium ferruginous; a sample from Guatemala is more yellowish, but may be faded.

The female differs from the worker in the usual ways, and is only slightly larger.

Male (taken from nest series with workers, Mixco, Guatemala) : TL 2.2, HL 0.43, WL 0.65, greatest diameter of compound eye 0.20, forewing L I.9 mm. Mandibles vestigial, not opposable, with truncate apices. Notauli indistinct. Propodeal teeth well-developed and acute. Petiole slender, with a long, low node. Gaster and mesokatepisternum smooth and shining, body otherwise densely punctulate, opaque. Fine slender erect hairs corresponding in large part to the erect hairs of worker and female, but only some of those on the alitrunk are broadened at their apices. Head blackish-brown; body ferruginous brown; mouthparts and appendages brownish-yellow.

Venation of forewing as in Smithistruma pergandei (Emery), shown in Wheeler's "Ants," fig. IID. Hind wing with 5 submedian hamuli. Volsella of genitalia shown in Figure 7.

Distribution: Known from southeastern and northeastern Brazil and Trinidad, so probably widespread also in the sparsely collected interior of South America. Common through Central America into southern Mexico. Except for Trinidad, unknown in the West Indies.

Localities for material examined: Brazil: Santa Catarina State, without further locality (Hetschko leg.), syntype of subedentata in MCZ. Agudos, S. Paulo State (W. W. Kempf leg.). Belém, Pará State (W. Beebe leg.). Trinidad: St. Augustine; Fyzabad; foothills north of Tunapuna; Arima-Blanchiseusse Road (all N. A. Weber leg.). Panama Canal Zone: Barro Colorado Island (leg. J. Zetek, N. A. Weber, E. C. Williams, Jr., E. S. McCluskey, W. L. Brown, Jr.), several collections, mostly from leaf litter and upper soil berlesates in forest. Costa Rica: Orijuaco (Tristan leg.), syntypes of tristani in MCZ. Turrucares (no collector cited). Guatemala: Trece Aguas, Alta Vera Paz (Schwarz and Barber leg.), 
syntypes of clavata in MCZ. Mixco (W. M. Mann leg.). Mexico, Veracruz: Peñuela, ca. 700 m. (H. S. Dybas leg.). Tetzonapa (Dybas leg.). Pueblo Nuevo, near Tetzonapa (E. O. Wilson leg.). Las Hamacas, I7 km. north of Santiago Tuxtla (Wilson leg.).

Biology: $S$. subedentata is primarily a species of the leaf litter and upper soil layers in mesic tropical forest. Nests have been found on the underside of a small $\log$ buried in leaf litter, in a small pocket in the soil, and among rotting leaves and twigs. In life, the workers are active huntresses, resembling workers of Strumigenys louisianae Roger in general appearance and behavior. E. O. Wilson (unpubl. notes) kept a colony from Veracruz alive and gave them a variety of small arthropods, among which they accepted as prey entomobryoid collembola, while ignoring over two days small millipeds, Reticulitermes nymphs, a small isopod, and an undetermined soft-bodied mite. The colonies so far found have contained from about 20 to 90 workers and one or more queens. Wasmann (I9I5) records a sample taken in southeastern Brazil from a nest of the termite Anoplotermes ater (Hagen).

\section{Strumigenys trieces new species}

(Figure 8)

Holotype worker: TL, 2.3, HL 0.58, ML 0.28, WL o.62 mm.; CI 78, MI 48. Similar to S. subedentata, but differing in the following characters:

I. Head proper relatively longer and narrower, and slightly more depressed.

2. Each inner mandibular margin with three small, acute, subequal teeth spaced out along its apical third.

3. Alitrunk, particularly promesonotum, depressed and only weakly convex; constriction at metanotum only slight as seen from above; metanotal groove obsolescent, marked by a broad, shallow dip in the dorsal profile as seen from the side.

4. Petiole and postpetiole more massive (broader) than in subedentata, the petiole with a shorter, thicker peduncle. Posterodorsal collar of petiole and ventral spongiform lobes of postpetiole a little larger than in subedentata.

5. Ground pilosity of head and alitrunk nearly or quite obsolete. Dorsum of head with three pairs of erect, slender remiform hairs, arranged as shown in Figure 8, except that the pair on the vertex is not shown in the figure. Similar slender, erect, remiform to truncate (or even bluntly pointed) hairs as follows: one pair on humeri; one 
pair on mesonotum; one pair on petiolar node; 3 pairs on postpetiole; probably originally 6 rows of 6 hairs each on gastric dorsum (some apparently rubbed off). Large hairs fringing inner mandibular margirs (not shown in Figure 8) linear-spatulate, with rounded ends, predominantly perpendicular to the shafts of the mandibles.

6. Punctulation denser and finer than in subedentata; gastric dorsum predominantly smooth and shining, with a few feeble longitudinal costulae occupying about the basal fifth of the first tergum. Color light ferruginous with slightly more brownish gaster.

Known only from the unique holotype worker $(\mathrm{MCZ})$, labeled "Costa Rica/ F. Nevermann/ I8.VII.31."

Key to the Species of the Strumigenys gundlachi Group, Based on Workers and Females

I. Antennal scape $0.33 \mathrm{~mm}$. or more long; large, dark-colored species with long mandibles (Fig. 4; Jamaica)

Antennal scape $<0.33 \mathrm{~mm}$. long

jamaicensis Brown

2. Mandibles short and thick $(M I<56)$; robust species, worker HL mostly $>0.48 \mathrm{~mm}$. 2. Mandibles longer and slender (MI 56 or more); smaller specis, worker HL mostly $0.48 \mathrm{~mm}$. or less ................................... 4 .

3. Mandible very short in proportion to head (MI 48 in unique holotype), with exactly three small preapical teeth; ground pilosity of head nearly or quite obsolete; pronotum markedly flattened (Fig. 8; Costa Rica) trieces Brown Mandible a little longer proportionate to head (MI 53-54), with more than three preapical denticles; ground pilosity abundant and conspicuous on head; promesonotum strongly rounded, not depressed (Fig. 9; s. Mexico to s. Brazil) .......... subedentata Mayr

4. Mandibles very long and slender $(\mathrm{MI}>7 \mathrm{O})$, bowed outward (Fig. 3; Trinidad to n. Argentina) ................. denticulata Mayr Mandibles not so long $(\mathrm{MI}<7 \mathrm{O})$, their shafts approximately straight 5 .

5. Spongiform appendages small but distinctly developed (Fig. 5); gastric dorsum of worker (when clean) predominantly smooth and shining, with a few basal costulae; female gaster commonly shagreened (Fig. I ; Caribbean countries) ...... gundlachi (Roger) Spongiform appendages obsolete (Fig. 6); gastric dorsum with distinct fine, mostly opaque reticulation (Fig. 2; Brazil, Bolivia, Caribbean countries) eggersi Emery 


\section{REFERENCES}

Brown, W. L., JR. 1948. A preliminary revision of the higher Dacetini. Trans. Amer. Ent. Soc., Philadelphia, 74: 101-129.

EMERY, C. 1890. Studi sulle formiche della faune neotropica I-V. Bull. Soc. Ent. Ital., 22: 38-80, pl. 5-9.

KEMPF, W. W. 1958. The ants of the tribe Dacetini in the State of Sa Paulo, Brazil, with the description of a new species of Strumigenys. Stud. Ent. (n. s.), Petrópolis, Brazil, 1: 553-560.

MaYr, G. 1887. Sudamerikanische Formiciden. Verh. zool.-bot. Ges. Wien, 37: 511-632.

Roger, J. 1862. Einige neue exotische Ameisen-Gattungen und Arten. Berlin. ent. Zeitschr., 6:233-262, 1. pl.

1863. Verzeichniss der Formiciden-Gattungen und Arten. Berlin.

Santschi, F. 1930. Quelques fourmis de Cuba et du Brésil. Bull. Soc. R. Ent. Égypte (n. s.), pp. 75-83.

1931. Fourmis de Cuba et de Panama. Rev. Ent., Rio de Janeiro, $1: 265-282$.

Wasmann, E. 1915. Das Gesellschaftsleben der Ameisen, I; as cited in Wheeler, W. M., 1936, Proc. Amer. Acad. Arts Sci., 71: 228-229.

WEBER, N. A. 1934. Notes on neotropical ants, including the descriptions of new forms. Rev. Ent., Rio de Janeiro, 4: 22-59.

1-7.

1952. Biological notes on Dacetini. Amer. Mus. Novit., 1554: 

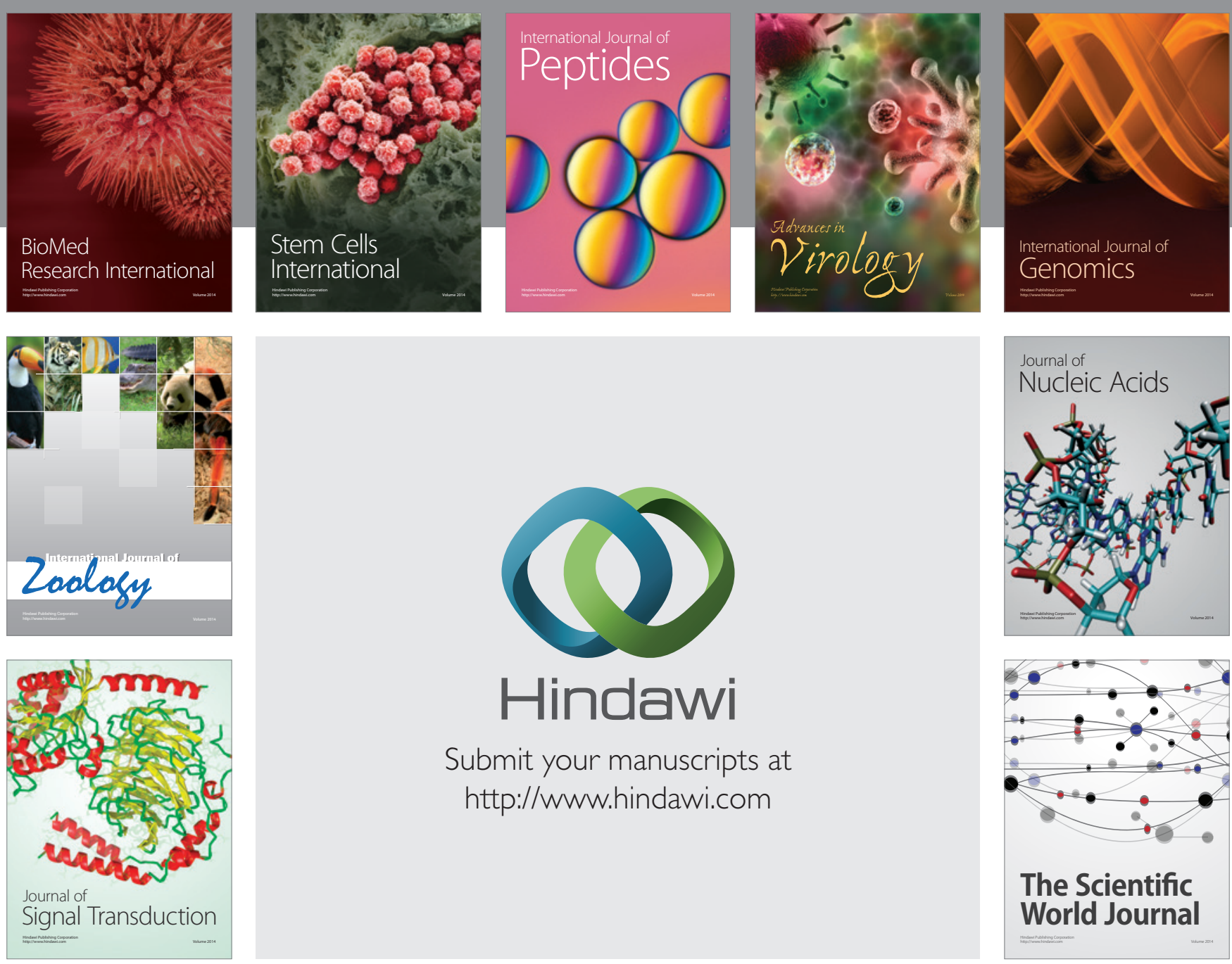

Submit your manuscripts at

http://www.hindawi.com
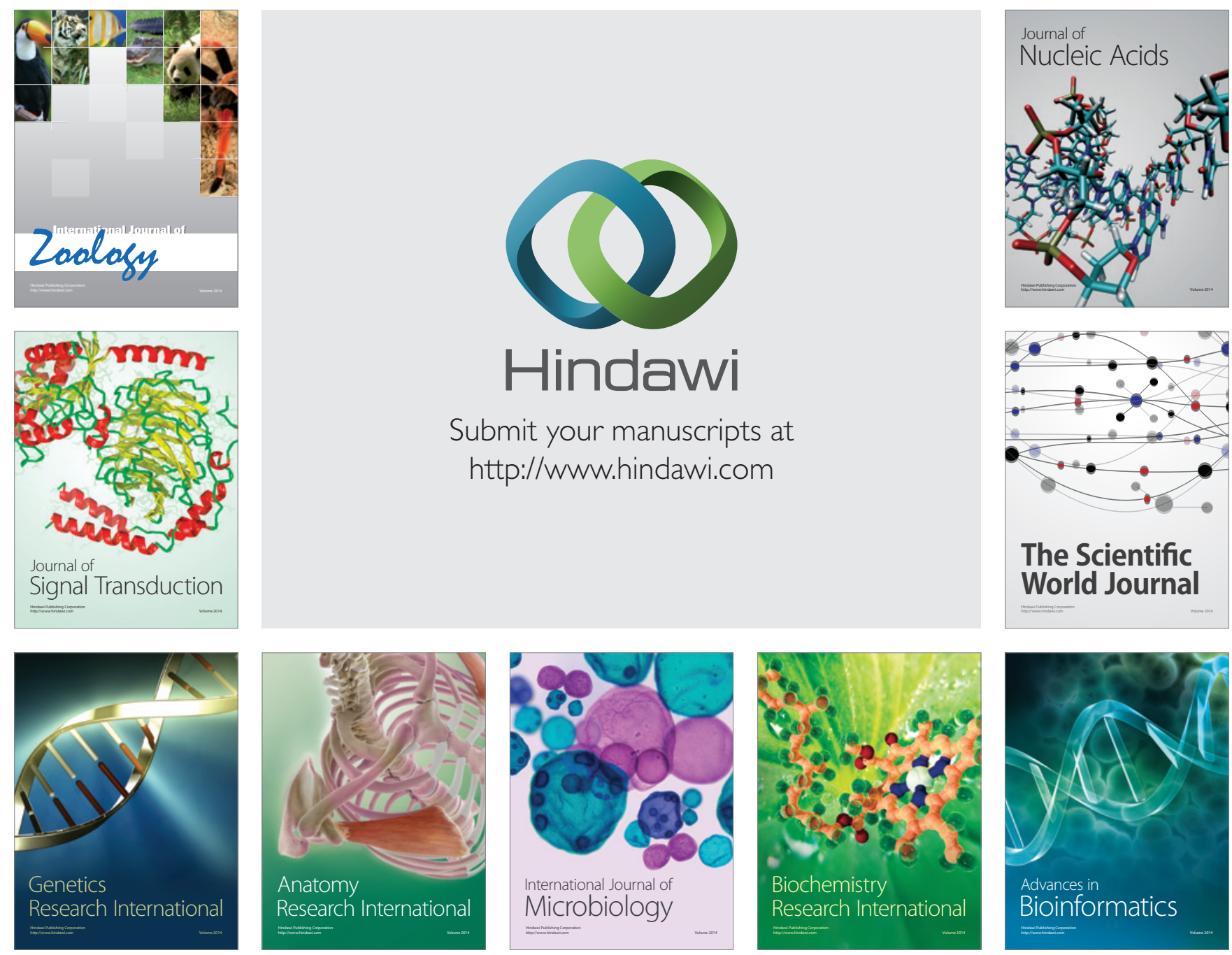

The Scientific World Journal
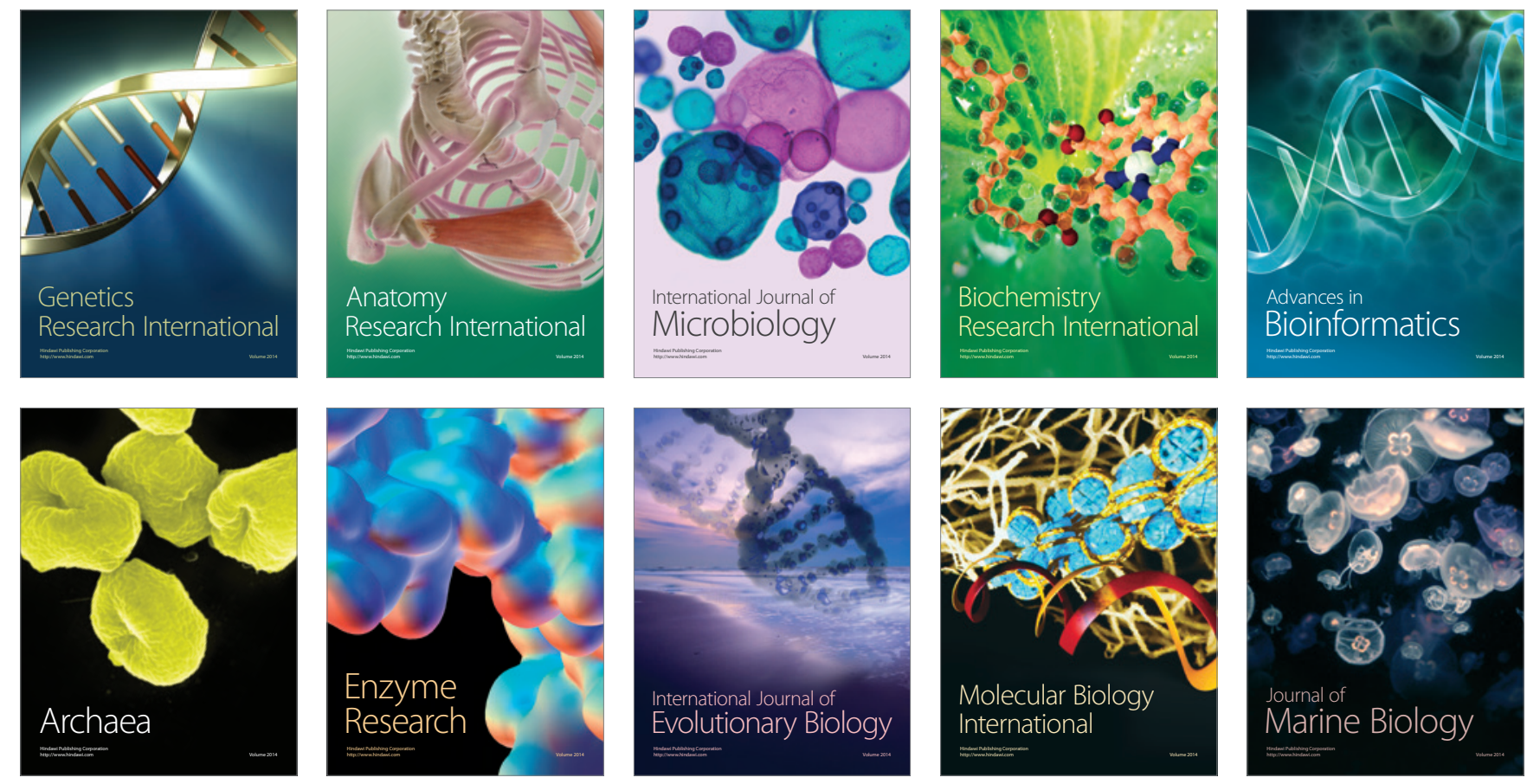